\title{
Deformation Behavior of Laser Welds in High Temperature Oxidation Resistant Fe-Cr-Al Alloys for Fuel Cladding Applications
}

\author{
Kevin G. Field ${ }^{1 *}$, Maxim N. Gussev ${ }^{2}$, Yukinori Yamamoto ${ }^{3}$, Lance L. Snead ${ }^{4}$ \\ 1,2,3,4 Oak Ridge National Laboratory, Oak Ridge, TN 37831, USA \\ 1 fieldkg@ornl.gov \\ 2 gussevmn@ornl.gov \\ 3 yamamotoy@ornl.gov \\ ${ }^{4}$ sneadll@ornl.gov
}

\begin{abstract}
Ferritic-structured $\mathrm{Fe}-\mathrm{Cr}-\mathrm{Al}$ alloys are being developed and show promise as oxidation resistant accident tolerant light water reactor fuel cladding. This study focuses on investigating the weldability and post-weld mechanical behavior of three model alloys in a range of Fe-(1317.5)Cr-(3-4.4)Al (wt.\%) with a minor addition of yttrium using modern laser-welding techniques. A detailed study on the mechanical performance of bead-on-plate welds using subsized, flat dog-bone tensile specimens and digital image correlation (DIC) has been carried out to determine the performance of welds as a function of alloy composition. Results indicated a reduction in the yield strength within the fusion zone compared to the base metal. Yield strength reduction was found to be primarily constrained to the fusion zone due to grain coarsening with a less severe reduction in the heat affected zone. For all proposed alloys, laser welding resulted in a defect free weld devoid of cracking or inclusions.
\end{abstract}

Keywords: FeCrAl alloys, Accident tolerant alloys Weld, Digital Image Correlation (DIC), true stress-true strain curves

(C) 2014. This manuscript version is made available under the Elsevier user license http://www.elsevier.com/open-access/userlicense/1.0/ 


\section{Introduction}

Many modern alloys, including zirconium based alloys, are known to degrade under accident scenarios in light water reactors (LWRs). In particular, above $1200{ }^{\circ} \mathrm{C}$ the consumption of Zr-alloys by steam or oxygen, with the associated release of hydrogen, becomes autocatalytic and in some cases is the major driver for heat input into loss of coolant accidents (LOCAs) [1-3]. Recent interest on enhanced accident tolerant materials, which display lower oxidation rates and reduced hydrogen production, has resulted in a renewed focus on iron-based alloys for fuel cladding materials. One sub-class of iron-based alloys, which has shown superior oxidation resistance in comparison to zirconium-based alloys, is Fe-Cr-Al alloys [2, 4]. These alloys utilize $\mathrm{Cr}$ additions for water corrosion resistance at normal operating temperatures and $\mathrm{Al}$ additions for increased high temperature oxidation resistance.

Although $\mathrm{Fe}-\mathrm{Cr}-\mathrm{Al}$ alloys have shown enhanced oxidation resistance in high temperature steam environments [2], little literature exists on other material parameters and fabrication techniques which could influence their adoption as an accident tolerant fuel cladding material. One parameter, which is critical to the fuel rod performance, is the integrity of the fuel rod end cap weld. Typical fuel elements utilize a circumferential weld in either a butt weld or corner weld configuration during final assembly $[5,6]$. Small amounts of contamination or weld defects such as pore formation can lead to costly fuel failures. Furthermore, the microstructural change in weld zones could lead to variations in the deformation behavior of the weld versus the base metal. Historically, Fe-Cr-Al based alloys have been reported to have poor weldability for fossil fuel, automotive, and weld clad applications [7-12]. Regina et al. indicated the weldability of single pass gas tungsten arc (GTA) welded Fe-Cr-Al based alloys is composition dependent, with increased $\mathrm{Cr}$ and $\mathrm{Al}$ additions leading to cracking in Fe-Cr-Al weldments [7]; however, advanced 
welding methods (e.g., laser welding) were not analyzed and those susceptible compositions previously reported had higher $\mathrm{Cr}$ and $\mathrm{Al}$ content than compositions currently being pursued for nuclear applications.

Under the larger program aiming at developing a nuclear grade "accident tolerant" Fe-Cr$\mathrm{Al}$ alloy, the compositions of interest can be contrasted with those of commercial interest (e.g. Kanthal APMT ${ }^{\mathrm{TM}}$ ) in that they are driving towards lower levels of $\mathrm{Cr}$ for enhanced radiation tolerance and are in the 4-6\% $\mathrm{Al}$ range $[13,14]$. The accident tolerant $\mathrm{Fe}-\mathrm{Cr}-\mathrm{Al}$ 's also include yttrium for enhanced high temperature oxidation. For the purposes of this study, a wider range of $\mathrm{Cr}$ and $\mathrm{Al}$ was considered and a series of model alloys were fabricated. Modern laser-welding techniques were utilized in this study as the large heat input in a small region results in reduced microstructural changes in the weldment.

\section{Materials and methods}

\subsection{Sample preparation}

Three model Fe-Cr-Al alloys: Fe-12Cr-4.4Al, Fe-15Cr-4Al, and Fe-17.5Cr-3Al were used in this study. The composition of each alloy is provided in Table 1 . The varying range of $\mathrm{Cr}$ and $\mathrm{Al}$ contents were selected to investigate alloying effects and to determine if there was an upper or lower threshold of $\mathrm{Cr}$ or $\mathrm{Al}$ additions for weldability of laser welded $\mathrm{Fe}-\mathrm{Cr}$ - $\mathrm{Al}$ alloys. Yttrium was added to expect better oxidation resistance of alumina forming alloys at elevated temperatures. The addition of Yttrium is known to reduce the growth rate of the oxide scales and improve the adherence resulting in improved oxidation resistance compared to that of base alloys which do not contain yttrium $[15,16]$. Starting materials were arc-melted by using pure element feed stocks, heat-treated and hot forged/rolled to control grain size to $20-50 \mu \mathrm{m}$, followed by flattening the sheet samples by applying cold rolling with $10 \%$ thickness reduction. The resulting 
sheet stock with a nominal thickness of $0.8 \mathrm{~mm}$ was used in this study. Samples for welding were mechanically cleaned to remove any surface oxides or contamination from the material processing steps before loading into the welding apparatus.

\subsection{Laser welding parameters}

A pulsed laser-welding machine was used. Preheating of the material being welded was not used and welding was conducted at room temperature. The specimens were held in the holder

of the laser-welder to perform autogenous, bead-on-plate welding. Welding was completed using a $102 \mathrm{~mm}$ focusing lens, with the following weld parameters: pulse length $7 \mathrm{~ms}, 25$ pulses/s, and $3 \mathrm{~mm} / \mathrm{s}$ welding speed in an inert argon cover gas. Lamp energy was adjusted to provide for full penetration welds with a $\sim 92 \%$ spot overlap. Linear welds were conducted parallel to the traverse rolling direction on each specimen. Post-weld visual inspection was conducted using a Keyence VHK-1000 confocal optical microscope (magnification up to $2 \mathrm{kx}$ ) on both the top and bottom side of the as-welded specimens to determine the amount, if any, of surface cracking.

\subsection{Metallography and microhardness traverses}

Weld specimens were cross-sectioned using a low speed diamond saw and polished to a mirror finish using standard metallographic procedures. Polished cross section specimens were etched using $50 \% \mathrm{H}_{2} \mathrm{O}+5 \% \mathrm{HNO}_{3}+1 \% \mathrm{HF}$ to reveal grain structure in the base, heat affected zone (HAZ), and fusion zone. Grain structure of the etched specimens was imaged using an Am Scope NMM-800RF/TRF optical microscope. Average grain diameter was calculated using the conventional linear mean intercept method [17].

Hardness traverses across the weld cross sections were conducted using a Wilson Model 402MVD Vickers Microhardness tester. The indent load was $300 \mathrm{~g}$ with a dwell time of $15 \mathrm{~s}$. Indent spacing was maintained at $0.2 \mathrm{~mm}$. Hardness tests were performed $\pm 2.6 \mathrm{~mm}$ from the 
centerline of each weld, which roughly corresponds to the gauge length of the sub-sized tensile specimens described in the following section.

\subsection{Mechanical testing}

Sub-sized, flat dog-bone tensile specimens of SS-J3 geometry were machined from the welded and non-welded sheet specimens where welded specimens had the fusion zone orientated perpendicular to the load direction. The cross-weld tensile specimen dimensions and location of the fusion zone within the specimen is shown in Figure 1. Sub-sized specimens were utilized to maximize data from the limited volume of material available for the study. Specimens were manufactured using electro-discharge machining (EDM). Care was taken to center the fusion zone in the gauge length of the specimen, though insignificant deviations from the ideal position occurred. At least two specimens were machined from each weld traverse to verify no outliers were used in the analysis. Specimens were imaged optically after machining to locate the fusion zone within the gauge length. Care was taken to document the weld direction and the extracted specimen location. Specimens were ground to 1200 grit $\mathrm{SiC}$ finish to provide a uniform thickness along the gauge length and remove the weld overbead and underbead to obtain weld properties. Specimens without welds were prepared using the same procedures.

Tensile tests were performed on a MTS Insight 2-52 one-column tensile screw machine. All tensile specimens were shoulder loaded and tested at room temperature with a strain rate of $1.1 \times 10^{-3} \mathrm{~s}^{-1}$. Prior to tensile tests, a subset of specimens were painted with a random speckle pattern. Several specimens were tested without speckle patterns to characterize deformation relief development; in this case side white light of controlled intensity was used to provide contrast details on the specimen surface. Surface speckle patterns allow for optical, non-contact strain measurements during tensile testing. Strain field measurements were calculated using VIC- 
2D commercial software and a custom program utilizing common digital image correlation (DIC) algorithms. The details of DIC method is presented elsewhere [18-20]. DIC allows for strain field measurements of base, HAZ, and weld metal on the same tensile specimen. Tensile tests were performed on sub-sized tensile specimens both with and without weldments. Nonwelded specimens provided a baseline observation of the mechanical properties of the model alloys.

\section{Results and discussion}

\subsection{Microstructural analysis and microhardness measurements}

It has been well known that $\mathrm{Fe}-\mathrm{Al}$ and $\mathrm{Fe}-\mathrm{Cr}-\mathrm{Al}$ welds with significant amounts of $\mathrm{Al}$ can be susceptible to cracking due to the formation of intermetallics or hydrogen embrittlement [7$12,21,22]$. Here, the $\mathrm{Al}$ content is maintained at levels where only ferrite formation is expected based on the ternary Fe-Cr-Al diagram [23]. Cross-sectional microstructures of the fusion zone, HAZ and base metal for each alloy are shown in Figure 2. The base material (outer regions) has a fine-grained ferrite structure with grain sizes in the range of 20-50 $\mu \mathrm{m}$ for all alloys. The fusion zone demonstrates a distinctly different structure with coarse ferrite grains emanating from the fusion line to the centerline of the weld. The delineation between the fusion line and the HAZ is difficult to distinguish optically, but recovery and recrystallization is expected in the HAZ due to the heat input from the welding process. No visible secondary phase particles were observed in any weldment. Fusion zones had widths on the order of 1-2 mm depending on the specimen and location along the weld traverse.

No signs of cracking, porosity or other defects were found within the weldments in either planar or cross-sectional investigations. Cross sectional and planar observations are consistent with the results of Regina et al. [7] who showed cracked-free welds in Fe-Cr-Al alloys with 
similar composition to those investigated here using GTA welding techniques.

Cross-weld hardness profiles for each alloy are presented in Figure 3 (left). Softening was observed in the fusion zone of all alloys with the Fe-17.5Cr-3Al showing the highest degree of softening compared to the base metal. Hardness changes were less pronounced in the Fe-12Cr4.4Al or Fe-15Cr-4Al alloys. The reduction in hardness and change in grain size is summarized for all alloys in Figure 3 (right). This figure shows that a decrease in hardness is related to the decrease in grain size although a direct correlation was not found. The large grain sizes in the fusion zone resulted in hardness tests only sampling one grain or two grains while the parent material sampled several grains within a single indent. Hardness profiles revealed a reduction in hardness about 1-2 mm out from the centerline of the weld. This reduction in hardness extends further than the apparent width of the fusion zone, indicating the thermal exposure at the HAZ is high enough to recover the cold-work applied to the base materials even though there is no apparent microstructure change.

\subsection{Tensile properties}

Figure 4 demonstrates the engineering tensile diagrams for the non-welded and welded specimens for each alloy. Three specimens per condition per alloy are displayed. Prior to welding, the specimens experienced uniform elongation less than 3-4\%. Strain softening of unwelded specimens is caused by cold working. Strain softening is present only in the engineering diagrams; true curves, as will be discussed below, show pronounced strain hardening behavior. Figure 5 summarizes the standard tensile properties of yield strength, ultimate tensile strength, uniform elongation, and total elongation for the specimens with and without welding. One can see that the yield strength and ultimate tensile strength of the welded specimens were lower than in the non-welded specimens. Welding led to an increase in the uniform elongation 
but the total elongation changed insignificantly. All three alloys demonstrated similar trends in the tensile properties between the base and weld metal.

It should be noted that based on the hardness data and optical observations, welded specimens were complex objects with a gradient of properties along the gauge length including grain size and hardness. Thus, the engineering diagrams (Fig. 4) and tensile properties (Fig. 5) show the superposition of material properties of all three zones and therefore provide a general, overall picture of the mechanical behavior of a welded specimen. For example, high total elongation values in Fig. 5 indicate that no embrittlement was introduced by welding, but brittle behavior within the fusion zone or some other area could be masked by an overall ductile behavior of the specimen.

\subsection{Local strain distribution during deformation}

To provide more detailed understanding of mechanical behavior, DIC analysis was conducted to determine the local strain distribution and deformation behavior of each region: base metal, HAZ, and fusion zone. The local strain distribution of each sample was calculated using commercially available VIC-2D software. The program uses a DIC algorithm to trace the speckle pattern through the set of experimental images during straining [18]. The strain distribution maps were cross-referenced with scaled optical images taken prior to mechanical cleaning to determine the location of the fusion zone in the strain distribution maps in the welded specimens. The analysis indicated the strain distribution along the gauge length of tensile specimens differs significantly between specimens containing a fusion zone and specimens without welding.

In the non-welded specimens, plastic deformation did not demonstrate a tendency to appear in a particular location and the location of the neck was random throughout all specimens 
tested. For example, Figure 6 (left) shows the strain distribution along the gauge of a non-welded Fe-17.5Cr-3Al specimen. This specimen, which is representative of all non-welded specimens, showed insignificant uniform deformation $(\sim 0.03)$ and then a peak of localized deformation with neck formation. Such strain distribution (uniform "plateau" along the gauge and "peak" of localized deformation) is typical for most cold-worked or highly irradiated materials [24]. Depending on the cold-work level and material properties, uniform deformation may or may not appear; for instance, highly irradiated austenitic steels ( 10 dpa or more) do not show any out-ofneck deformation [24].

In contrast, plastic deformation in welded specimens was non-random; plastic deformation always initiated in the fusion zone resulting in necking. Final fracture of the welded specimens always occurred inside the fusion zone for the specimens investigated. For example, Figure 6 (right) shows strain distribution along the gauge of a representative welded $\mathrm{Fe}-17.5 \mathrm{Cr}$ 3Al specimen. The plastic strain distribution had a specific delta-like (dispersed Gaussian) shape with the maximum strain corresponding to the middle of the fusion zone. The strain distribution did not show any sharp transitions between the fusion zone and HAZ or HAZ and base metal.

The strain distribution maps mimicked the hardness profile traverses shown in Figure 3 with a broad delta-like shape. Based on the hardness traverses and strain distribution maps it can be concluded the local strength level of the material in the fusion zone is lower than the strength of the parent zone, most likely a result from grain coarsening in the fusion zone. Alloying variations was found to have no influence on the local strain distribution in welded specimens. To determine the strength of each zone, further analysis was conducted to compute the true stress-strain behavior in each zone of each specimen tested.

\section{$3.4 \quad$ True stress-strain behavior of deformed specimens}


Defining the true stress - true strain curves or corresponding constitutive equation is one of the best ways to characterize mechanical behavior of a material [25]. For large welds, microspecimens may be produced directly from the weld and parent material to provide spatially homogeneous objects. For instance, Molak et al. [26] produced and tested micro-specimens with $2.3 \mathrm{~mm}$ gauge (overall length $5.5 \mathrm{~mm}$ ) to characterize weld and HAZ in thick plate of 316 steel. In the present work, however, micro-specimen production was not possible. Furthermore, inreactor materials testing typically limits the total specimen volume driving for the need of subsized tensile specimens. As a result, conventional tensile tests with optic imaging were conducted with welded specimens; the experimental approach was close to method utilized by Turski et al. [27] and Touboul et al. [28] during investigation of welded specimen with spatial variation of strength.

True stress - true strain curves were calculated using a custom made program. The program uses a common DIC algorithm [18], similar to one used in VIC-2D, to trace selected points through the set of experimental images. True stress was calculated using "constant volume criteria" [20]. This criterion assumes that the volume and density of material does not change or changes insignificantly during plastic deformation. It should be noted the "constant volume criteria" noted above assumes uniform uniaxial stress state. Neck formation and development lead to the formation of a complex stress state, and there are three principal stresses in the neck. However, in the case of the present work the complex stress state may be neglected since the strain level is relatively low.

True stress-true strain curves were determined for several regions along the gauge length of welded specimens. Specifically, curves were measured for the fusion area, the HAZ within $\sim 1.2 \mathrm{~mm}$ from the fusion zone, the region within $\sim 2.4 \mathrm{~mm}$ from the fusion zone centerline (R1) 
and the region sufficiently far from the fusion zone, $\sim 3.2 \mathrm{~mm}$ away from the centerline (R2). An example of the regions of interest for calculating the true stress - true strain curves can be found in Figure 7 (left). Partitioning of data along the gauge length of each specimen allows for analysis of length scale effects due to the laser welding process and fully characterizes the crosssectional width of the weldment. It is important to note that local properties changed smoothly inside the HAZ and any region examined [27], so each true curve represented average properties and behavior of the material inside of the partitioned region.

Figure 7 (right) shows an example of calculated true curves for a welded specimen of the Fe-15Cr-4Al alloy. The magnitude of deformation hardening for the fusion zone material is significantly higher than for a non-welded specimen. Based on the true stress - true strain curves the local yield stress values were determined for each partitioned region. A summary of the yield stress for each region is given in Table 2.

As it follows from Figure 7 and Table 2, the fusion zone exhibited the lowest yield stress value, as expected from the hardness traverses and strain distribution maps. The fusion zone demonstrated the lowest yield stress across all alloys investigated, although the highest Cr alloy, Fe-17.5Cr-3Al, showed the lowest yield stress in the fusion zone which is inline with the hardness data presented prior (Fig. 3). For all alloys, the yield stress increased as the distance from the fusion zone centerline increased. The Fe-12Cr-4.4Al alloy showed the highest resistance to yield stress reduction in the weldment.

The true stress - true strain curves corroborate the results generated from hardness traverses. The heat input from welding lead to melting and solidification, followed by grain growth emanating from the fusion line to the centerline. It also leads to softening in the HAZ due to recovery of the cold work applied to the base materials. The result on mechanical properties 
included delta-like strain distribution and lowered yield stress in the fusion zone and HAZ compared to non-welded specimens. The local yield stress distribution may be significantly different for large thickness material [27] or different welding methods [29].

No welding induced embrittlement or cracking was observed using any characterization and evaluation techniques in the present study. Since the degree of welding induced softening is known for each alloy, a thickness gradient may be used to compensate the strength loss caused by welding. The welding trials were performed on model alloys, devoid of secondary phases and complex microstructure. Based on these model alloys, limited affects due to $\mathrm{Cr}$ or $\mathrm{Al}$ content were observed.

It should be noted that these results are not transferable to oxide dispersion strengthened (ODS) FeCrAl alloys produced via powder metallurgy (e.g. Kanthal APMTTM). FeCrAl-ODS alloys have been known to show agglomeration of oxide clusters in the fusion zone leading to significant changes in the properties of the weld over the parent material [30-32]. More complex alloys, such as alloys with minor alloying additions other than $\mathrm{Cr}$ and $\mathrm{Al}$ or ODS alloys could generate significantly different results than those seen within this work.

\section{Conclusions}

The weldability and deformation behavior of three specially developed model-nuclear grade accident tolerant Fe-Cr-Al alloys were investigated and shown to have no strong function of $\mathrm{Cr}$ or Al. Use of sub-sized tensile specimens coupled with DIC allowed for detailed investigations in the local strain distribution. Several key conclusions were made based on these investigations: 
- Laser welding leads to a strength level decrease due to localized material annealing, grain growth, recrystallization and recovery of cold-work in the HAZ. The Fe-12Cr-4.4Al alloy showed the highest resistance to yield stress reduction in the weldment.

- In welded specimens, necking always occurred in the fusion zone. Fracture was also associated with fusion zone.

- No evidence of welding-caused embrittlement was observed; for all alloys, the material in the fusion areas demonstrated ductile behavior and high local plasticity level.

- Limited effect of varying the $\mathrm{Al}$ and $\mathrm{Cr}$ content of $\mathrm{Fe}-\mathrm{Cr}-\mathrm{Al}$ alloys was found on the weldability for the compositions of Fe-Cr-Al model alloys studied.

\section{Acknowledgements}

This research was funded by the U.S. Department of Energy’s Office of Nuclear Energy, Advanced Fuel Campaign of the Fuel Cycle R\&D program. Authors would like to thank D.A. Fredrick and R.G. Miller from Oak Ridge National Laboratory for their fruitful discussions and assistance with conducting the welding trials.

This manuscript has been authored by the Oak Ridge National Laboratory, managed by UT-Battelle LLC under Contract No. DE-AC05-00OR22725 with the US Department of Energy. The US Government retains and the publisher, by accepting the article for publication, acknowledges that the US Government retains a nonexclusive, paid-up, irrevocable, worldwide license to publish or reproduce the published form of this manuscript, or allow others to do so, for US Government purposes. 


\section{Table and Figures}

Table 1: Composition (wt. \%) of candidate Fe-Cr-Al alloys

\begin{tabular}{ccccc}
\hline \hline Alloy & Fe & $\mathrm{Cr}$ & $\mathrm{Al}$ & $\mathrm{Y}$ \\
\hline Fe-12Cr-4.4Al & Bal. & 11.96 & 4.42 & 0.027 \\
Fe-15Cr-4Al & Bal. & 15.03 & 3.92 & 0.035 \\
Fe-17.5Cr-3Al & Bal. & 17.51 & 2.93 & 0.017 \\
\hline \hline
\end{tabular}

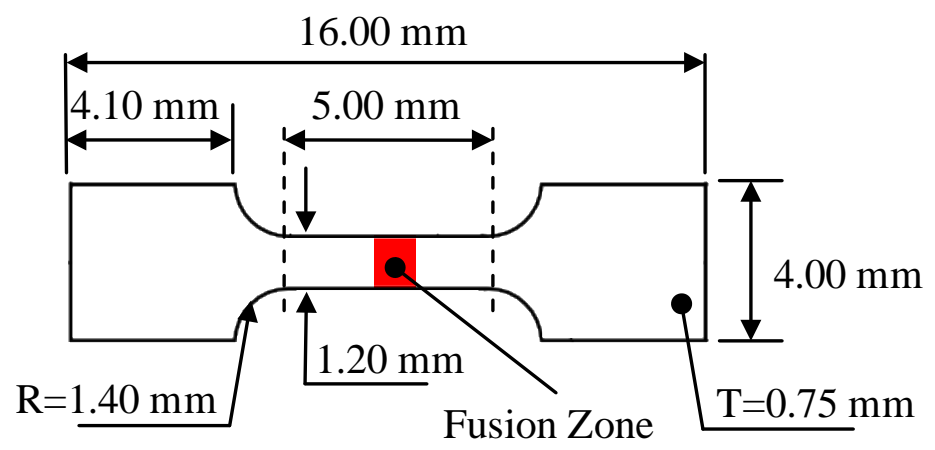

Figure 1: SS-J3 sub-sized tensile specimen geometry for welded and non-welded specimens. The filled polygon in the center indicates approximant location of the fusion zone for welded specimens. 

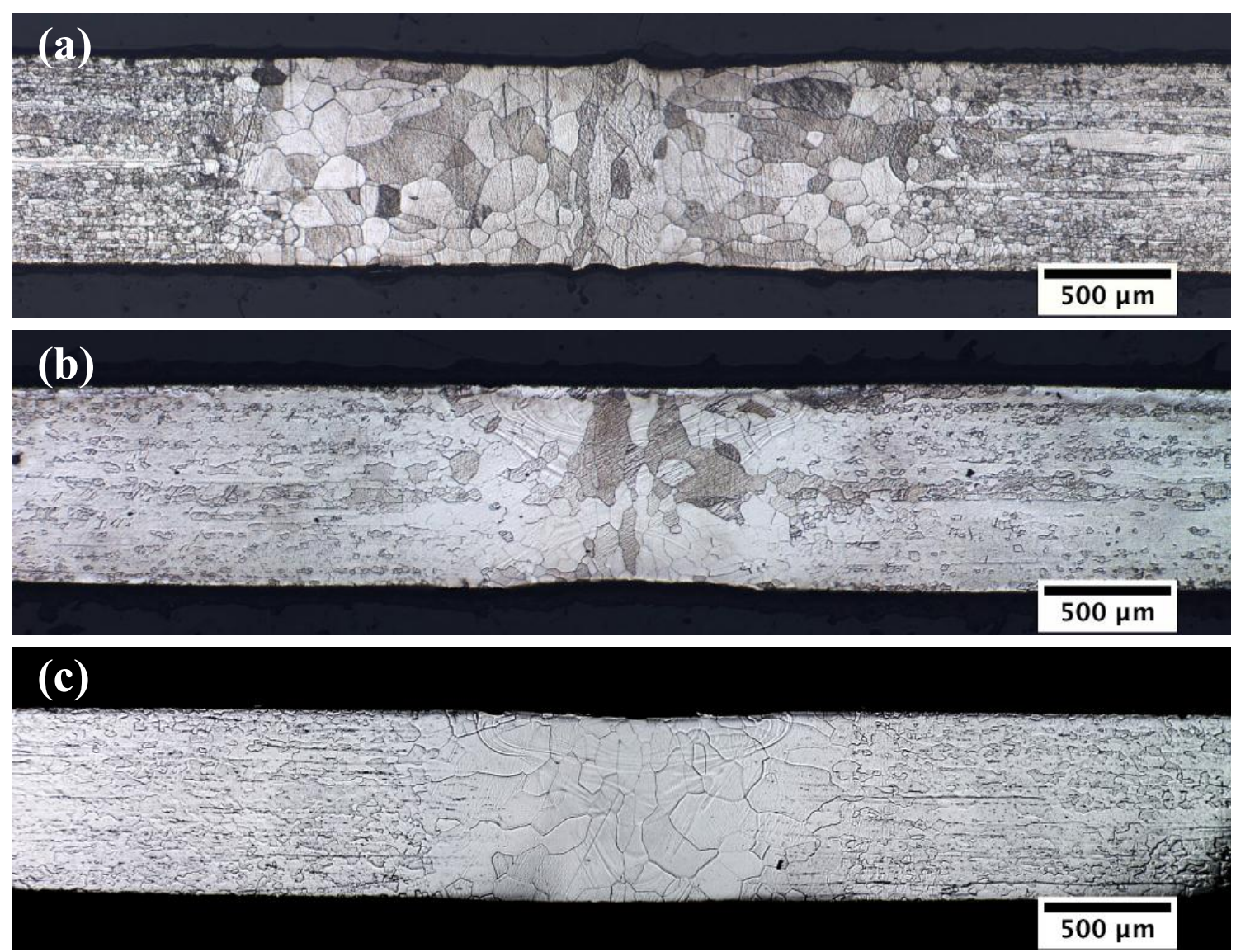

Figure 2: Optical micrographs illustrating the fusion zone, HAZ, and base metal for candidate alloys: (a) Fe-12Cr-4.4Al, (b) Fe-15Cr-4Al, and (c) Fe-17.5Cr-3Al. Apparent widths of fusion zone vary in the micrographs due to location along the weld. 

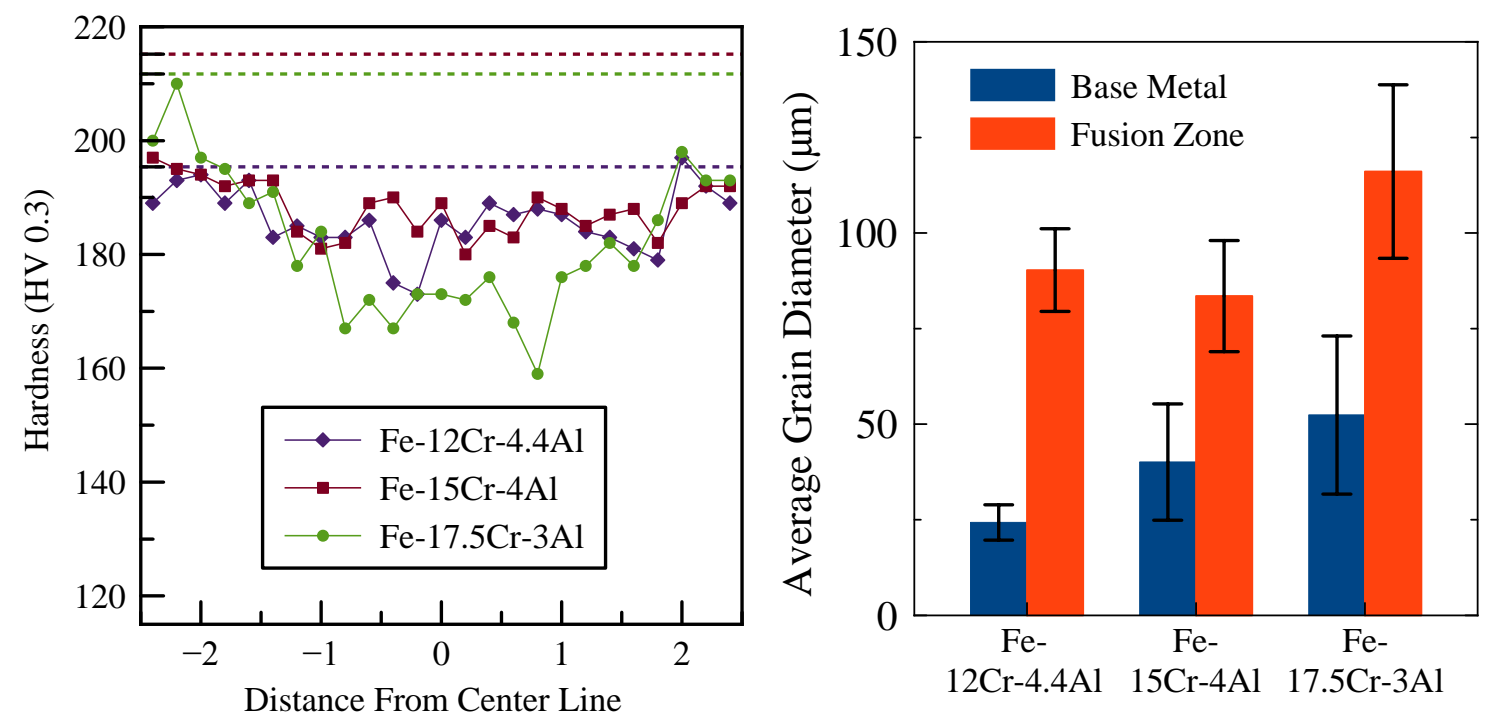

Figure 3: Relationship between grain size and hardness in welded model high temperature oxidation resistant Fe-Cr-Al alloys: (left) Hardness traverses across fusion zone and HAZ, dashed lines mark the base hardness values for the alloys investigated; (right) grain size of base metal and weldment. 

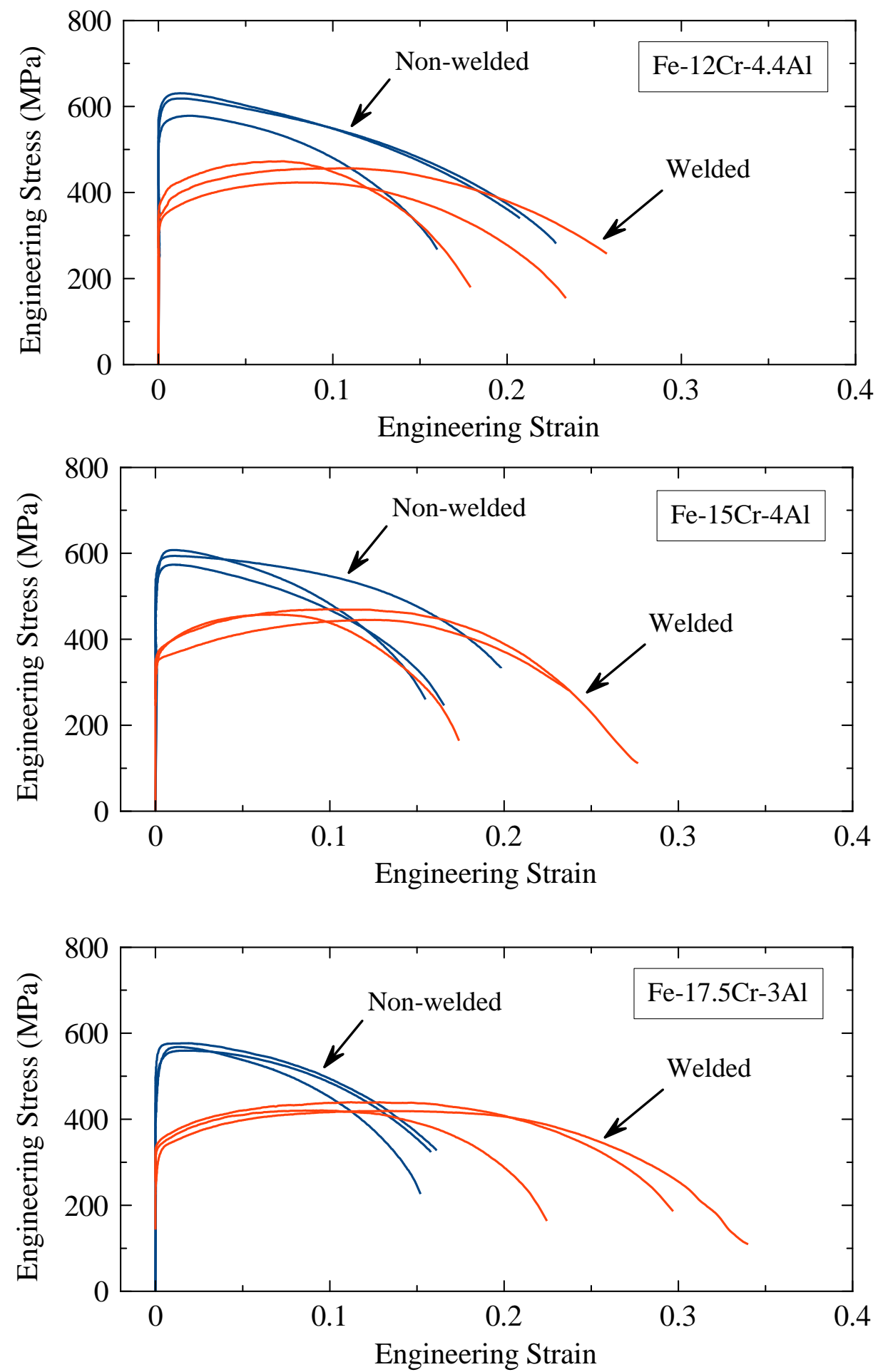

Figure 4: Engineering diagrams for tensile tests performed on subsized tensile specimens with welds (red) and without welds (blue): (top) Fe-12Cr-4.4Al, (middle) $\mathrm{Fe}-15 \mathrm{Cr}-4 \mathrm{Al}$, and (bottom) Fe-17.5Cr-3Al. 

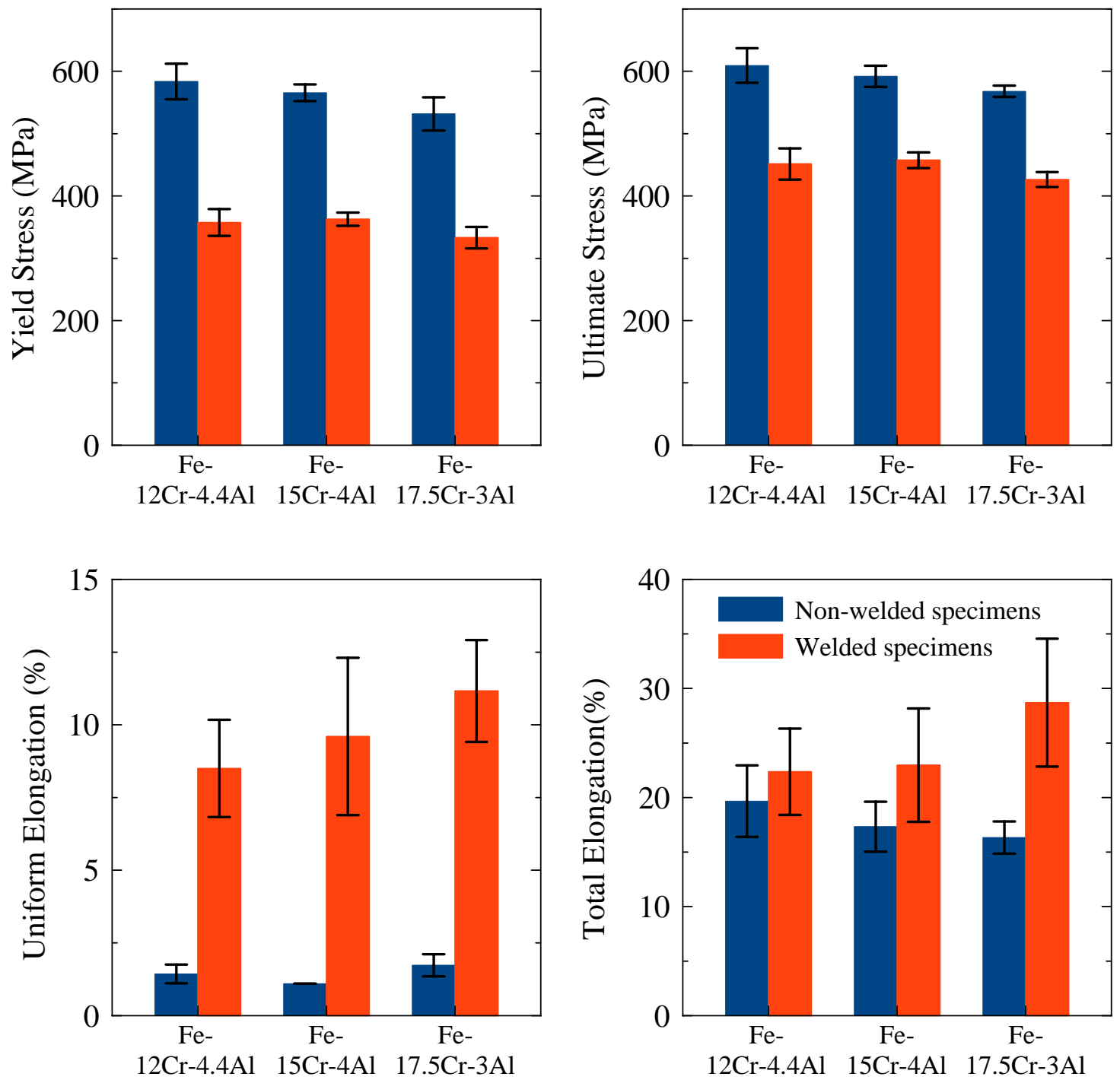

Figure 5: Summary of values of yield stress, ultimate stress, uniform elongation, and total elongation for the base alloy and weldment determined using sub-sized tensile specimens. Error bars report one standard deviation of the mean based on the three samples for each alloy in Fig. 4. 

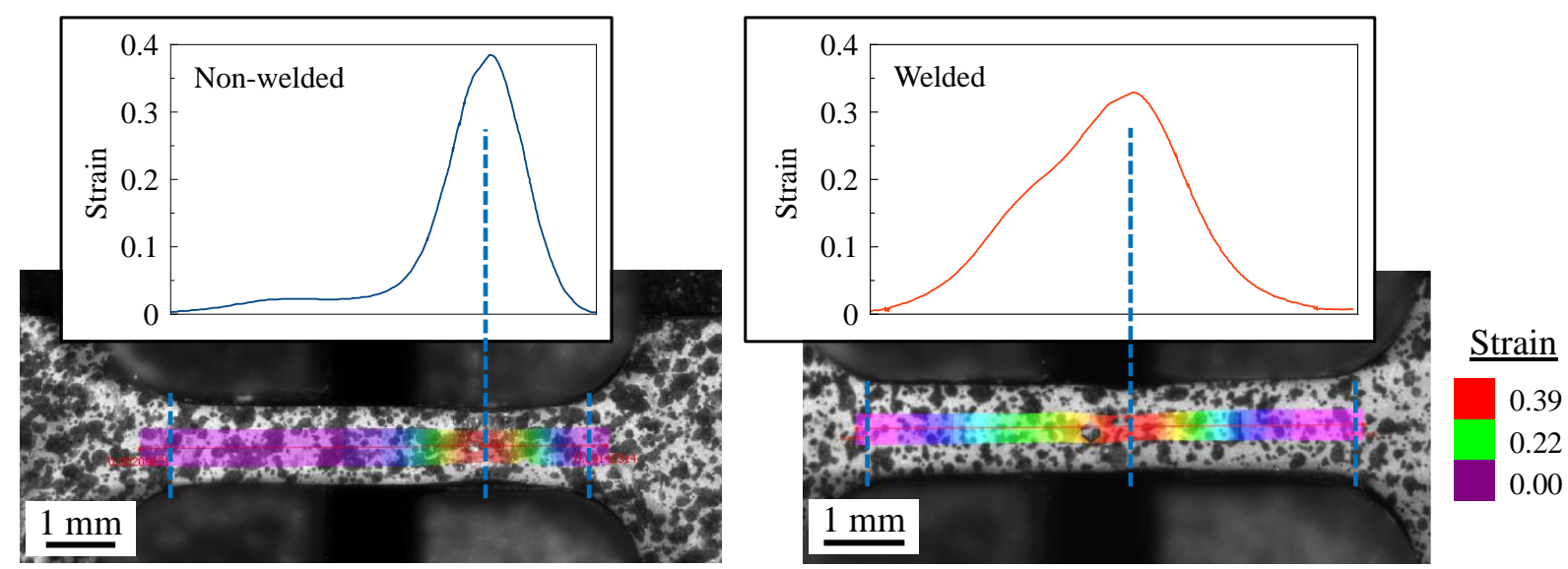

Figure 6: Strain distribution (Green's strain tensor) along the gauge length of sub-sized tensile specimens: (a) non-welded Fe-17.5Cr-3Al, (b) welded Fe-17.5Cr-3Al.
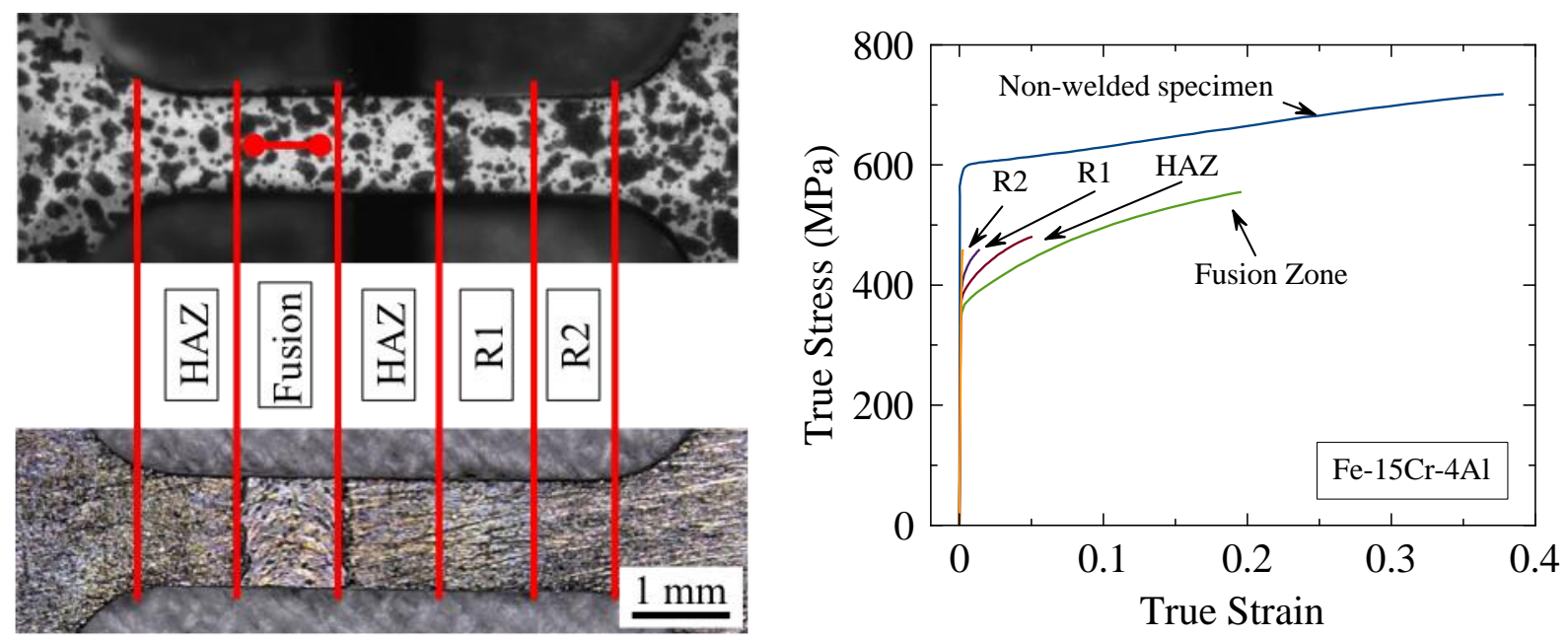

Figure 7. Location map (left) for true stress - true strain curves (right) for different regions along the gauge length of a $\mathrm{Fe}-15 \mathrm{Cr}-4 \mathrm{Al}$ welded specimens.

Table 2: Estimated yield stress values for different regions along a weld for each alloy studied.

\begin{tabular}{lccccc}
\hline \multicolumn{1}{c}{ Alloy } & $\begin{array}{c}\text { Fusion } \\
\text { area }(\mathrm{MPa})\end{array}$ & $\begin{array}{c}\mathrm{HAZ} \\
(\mathrm{MPa})\end{array}$ & $\begin{array}{c}\mathrm{R} 1 \\
(\mathrm{MPa})\end{array}$ & $\begin{array}{c}\mathrm{R} 2 \\
(\mathrm{MPa})\end{array}$ & $\begin{array}{c}\text { Parent } \\
\text { material } \\
(\mathrm{MPa})\end{array}$ \\
\hline $\mathrm{Fe}-12 \mathrm{Cr}-4.4 \mathrm{Al}$ & 360 & 390 & 430 & $\mathrm{n} / \mathrm{a}$ & 584 \\
$\mathrm{Fe}-15 \mathrm{Cr}-4 \mathrm{Al}$ & 360 & 375 & 400 & 460 & 566 \\
$\mathrm{Fe}-17.5 \mathrm{Cr}-3 \mathrm{Al}$ & 340 & 340 & 372 & $\mathrm{n} / \mathrm{a}$ & 532 \\
\hline \hline
\end{tabular}




\section{References}

[1] M. Moalem, D.R. Olander, Oxidation of Zircaloy by steam, Journal of Nuclear Materials, 182 (1991) 170-194.

[2] B.A. Pint, K.A. Terrani, M.P. Brady, T. Cheng, J.R. Keiser, High temperature oxidation of fuel cladding candidate materials in steam-hydrogen environments, Journal of Nuclear Materials, 440 (2013) 420-427.

[3] M.T. Farmer, L. Leibowitz, K.A. Terrani, K.R. Robb, Scoping assessments of ATF impact on late-stage accident progression including molten core-concrete interaction, Journal of Nuclear Materials, 448 (2014) 534-540.

[4] K.A. Terrani, S.J. Zinkle, L.L. Snead, Advanced oxidation-resistant iron-based alloys for LWR fuel cladding, Journal of Nuclear Materials, 448 (2013) 420-435.

[5] T.R.G. Kutty, C. Ganguly, Identation creep of Zircaloy-2 welds of nuclear fuel pins, Journal of Nuclear Materials, 207 (1993) 345-349.

[6] M. Ahmad, J.I. Akhter, M.A. Shaikh, M. Akhtar, M. Iqbal, M.A. Chaudhry, Hardness and microstructural studies of electron beam welded joints of Zircaloy-4 and stainless steel, Journal of Nuclear Materials, 301 (2002) 118-121.

[7] J.R. Regina, J.N. Dupont, A.R. Marder, The effect of chromium on the weldability and microstructure of Fe-Cr-Al weld cladding, Welding Journal, 86 (2007) 170-178.

[8] H. El Kadiri, Y. Bienvenu, K. Solanki, M.F. Horstemeyer, P.T. Wang, Creep and tensile behaviors of $\mathrm{Fe}-\mathrm{Cr}-\mathrm{Al}$ foils and laser microwelds at high temperature, Materials Science and Engineering: A, 421 (2006) 168-181.

[9] J. Tusek, A. Kosmac, U. Nartnik, A. Dejan, Welding of heat-resistant $20 \% \mathrm{Cr}-5 \% \mathrm{Al}$ steels, Z. Metallkd., 93 (2002) 310-314.

[10] N.A. McPherson, H. Samson, T.N. Baker, N. Suarez-Fernandez, Steel microstructures in autogenous laser welds, Journal of Laser Applications, 15 (2003) 200-210.

[11] E.M. El-Giar, M.A. Zaeem, H. El Kadiri, R.S. Florea, H. Rhee, Y. Bienvenu, M. Dahmen, T. Malot, M. Cherkaoui, On laser welding of thin steel sheets, Science and Technology of Welding \& Joining, 17 (2012) 571-580.

[12] S.W. Banovic, J.N. DuPont, P.F. Tortorelli, A.R. Marder, The role of aluminum on the weldability and sulfidation behavior of iron-aluminum cladding, Welding Journal, 48 (1999) 2330.

[13] Y. Yamamoto, B.A. Pint, K.A. Terrani, K.G. Field, L.L. Snead, M3FT-13OR0202291: Development of improved ATF engineering alloy - CALPHAD calculations and initial billet production, in, Oak Ridge National Laboratory, Oak Ridge, TN, 2013. 
[14] Y. Yamamoto, Y. Yang, K.G. Field, K.A. Terrani, B.A. Pint, L.L. Snead, M3FT14OR0202232: Letter Report Documenting Progress of Second Generation ATF FeCrAl Alloy Fabrication, in, Oak Ridge National Laboration, Oak Ridge, TN, 2014.

[15] B.A. Pint, Optimization of Reactive-Element Additions to Improve Oxidation Performance of Alumina-Forming Alloys, Journal of American Ceramic Society, 86 (2003) 686-695.

[16] B.A. Pint, Experimental Observations in Support of the Dynamic-Segregation Theory to Explain the Reactive-Element Effect, Oxidation of Metals, 45 (1995) 1-37.

[17] ASTM, Standard Test Methods for Determining Average Grain Size, in: E112-12, ASTM International, West Conshohocken, PA, 2012.

[18] B. Pan, K. Qian, H. Xie, A. Asundi, Two-dimensional digital image correlation for in-plane displacement and strain measurement: a review, Measurement Science and Technology, 20 (2009) 062001.

[19] K. Suzuki, S. Jitsukawa, N. Okubo, F. Takada, Intensely irradiated steel components: Plastic and fracture properties, and a new concept of structural design criteria for assuring the structural integrity, Nuclear Engineering and Design, 240 (2010) 1290-1305.

[20] M.N. Gussev, O.P. Maksimkin, I.S. Osipov, F. Garner, Application of Digital Marker Extensometry to Determine the True Stress-Strain Behavior of Irradiated Metals and Alloys, Journal of ASTM International, 5 (2008).

[21] C.T. Liu, E.H. Lee, C.G. McKamey, An environmental effect as the major cause for roomtemperature embrittlement in FeAl, Scripta metallurgica, 23 (1989) 875-880.

[22] J.N. Dupont, J.R. Regina, K. Adams, Improving the weldability of fecral weld overlay coatings, in: Fossil Energy Materials Conference, ORNL, Oak Ridge National Laboratory, 2007, pp. 131-137.

[23] P. Villars, A. Prince, H. Okamoto, Handbook of Ternary Alloy Phase Diagrams, ASM International, 1995.

[24] M.N. Gusev, O.P. Maksimkin, F.A. Garner, Peculiarities of plastic flow involving "deformation waves" observed during low-temperature tensile tests of highly irradiated 12Cr18Ni10Ti and 08Cr16Ni11Mo3 steels, Journal of Nuclear Materials, 403 (2010) 121-125.

[25] M.N. Gussev, T.S. Byun, J.T. Busby, Description of strain hardening behavior in neutronirradiated fcc metals, Journal of Nuclear Materials, 427 (2012) 62-68.

[26] R.M. Molak, K. Paradowski, T. Brynk, L. Ciupinski, Z. Pakiela, K.J. Kurzydlowski, Measurement of mechanical properties in a $316 \mathrm{~L}$ stainless steel welded joint, International Journal of Pressure Vessels and Piping, 86 (2009) 43-47. 
[27] M. Turski, M.C. Smith, P.J. Bouchard, L. Edwards, P.J. Withers, Spatially Resolved Materials Property Data From a Uniaxial Cross-Weld Tensile Test, Journal of Pressure Vessel Technology, 131 (2009).

[28] M. Touboul, J. Crepin, G. Rousselier, F. Latourte, S. Leclercq, Identification of Local Viscoplastic Properties in P91 Welds from Full Field Measurements at Room Temperature and $625^{\circ} \mathrm{C}$, Experimental Mechanics, 53 (2012) 455-468.

[29] G.M. Castelluccio, A.A. Yawny, J.E.P. Ipina, H.A. Ernst, In Situ Evaluation of Tensile Properties of Heat-Affected Zones from Welded Steel Pipes, Strain, 48 (2012) 68-74.

[30] N. Baluc, D.S. Gelles, S. Jitsukawa, A. Kimura, R.L. Klueh, G.R. Odette, B. van der Schaaf, $\mathrm{J}$. Yu, Status of reduced activation ferritic/martensitic steel development, Journal of Nuclear Materials, 367-370 (2007) 33-41.

[31] C.Y. Kang, T.H. North, D.D. Perovic, Microstructural Features of Friction Welded MA 956 Superalloy Material, Metallurgical and Mateirals Transactions A, 27A (1996) 4019-4029.

[32] P.A. Molian, Y.M. Yang, P.C. Patnaik, Laser welding of oxide dispersion-strengthened alloy MA754, Journal of Materials Science, 27 (1992) 2687-2694. 